\title{
Days of Delirium Are Associated with 1-Year Mortality in an Older Intensive Care Unit Population
}

\author{
Margaret A. Pisani ${ }^{1}$, So Yeon Joyce Kong ${ }^{2}$, Stanislav V. Kas| ${ }^{2}$, Terrence E. Murphy ${ }^{3}$, Katy L. B. Araujo ${ }^{3}$, and \\ Peter H. Van Ness 2,3 \\ ${ }^{1}$ Department of Internal Medicine, Pulmonary \& Critical Care Section, and the Program on Aging, Yale University School of Medicine, New Haven; \\ ${ }^{2}$ Yale School of Public Health, New Haven, and ${ }^{3}$ Department of Internal Medicine, Geriatrics Section, and the Program on Aging, Yale University \\ School of Medicine, New Haven, Connecticut
}

\begin{abstract}
Rationale: Delirium is a frequent occurrence in older intensive care unit (ICU) patients, but the importance of the duration of delirium in contributing to adverse long-term outcomes is unclear.

Objectives: To examine the association of the number of days of ICU delirium with mortality in an older patient population.

Methods: We performed a prospective cohort study in a 14-bed ICU in an urban acute care hospital. The patient population comprised 304 consecutive admissions 60 years of age and older.

Measurements and Main Results: The main outcome was 1-year mortality after ICU admission. Patients were assessed daily for delirium with the Confusion Assessment Method for the ICU and a validated chart review method. The median duration of ICU delirium was 3 days (range, 1-46 d). During the follow-up period, $153(50 \%)$ patients died. After adjusting for relevant covariates, including age, severity of illness, comorbid conditions, psychoactive medication use, and baseline cognitive and functional status, the number of days of ICU delirium was significantly associated with time to death within 1 year post-ICU admission (hazard ratio, 1.10; $95 \%$ confidence interval, 1.02-1.18).

Conclusions: Number of days of ICU delirium was associated with higher 1-year mortality after adjustment for relevant covariates in an older ICU population. Investigations should be undertaken to reduce the number of days of ICU delirium and to study the impact of this reduction on important health outcomes, including mortality and functional and cognitive status.
\end{abstract}

Keywords: delirium; aging; mortality; intensive care

Delirium in the intensive care unit (ICU) is a common condition for hospitalized older patients due to the severity of their illnesses, the number of their comorbidities, and their advanced age (1-3). The development of delirium has been associated with higher morbidity, persistent functional decline, longer hospital stays, and increased costs (4-9). Previous studies have shown delirium to be associated with increased mortality $(6,10$ 12). Although numerous studies have documented an increased risk of mortality associated with the occurrence of delirium, to our knowledge, no investigations have focused on the effect of the number days of ICU delirium on mortality. Examining the impact of days of delirium as opposed to just the presence of delirium is particularly relevant in an ICU setting. Our prior research has demonstrated that the majority of patients present with delirium or develop delerium within the first 48 hours (3), thus making prevention of delirium challenging. Demonstrating

(Received in original form April 7, 2009; accepted in final form September 10, 2009) Supported by the Claude D. Pepper Older Americans Independence Center at Yale University School of Medicine (P30AG021342); the T. Franklin Williams Geriatric Development Initiative through The CHEST Foundation, ASP, Hartford Foundation; and the National Institute on Aging (K23AG23023).

Correspondence and requests for reprints should be addressed to Margaret A. Pisani, M.D., M.P.H., Yale University School of Medicine, 333 Cedar Street, P.O. Box 208057, New Haven, CT 06520-8057. E-mail: Margaret.Pisani@yale.edu

Am J Respir Crit Care Med Vol 180. pp 1092-1097, 2009

Originally Published in Press as DOI: 10.1164/rccm.200904-0537OC on September 10, 2009 Internet address: www.atsjournals.org

\section{AT A GLANCE COMMENTARY}

Scientific Knowledge on the Subject

Older patients with critical illness are at risk for delirium, which can affect morbidity and mortality.

What This Study Adds to the Field

The number of days of delirium older patients experience during an intensive care unit admission is significantly associated with mortality up to 1 year after admission after controlling for severity of illness. These findings make it imperative to find ways to reduce duration of delirium in the intensive care unit.

that the number of days of delirium is an important marker of adverse outcomes will lead clinicians and investigators to examine ways to reduce days of delirium. The objective of this study was to examine the association between number of days of ICU delirium and mortality after adjusting for important comorbidities and other covariates among older ICU patients.

\section{METHODS}

The study participants were 304 consecutive patients 60 years of age or older who were admitted to the medical ICU at Yale-New Haven Hospital from September 5, 2002, through September 2004. Figure 1 presents the enrollment data for the study participants. Informed consent for participation was obtained from proxy respondents according to procedures approved by the Institutional Review Board of Yale University School of Medicine. Patients were critically ill; therefore, proxy respondents were also used as the primary source of baseline information as previously described $(13,14)$. Medical records were reviewed to obtain information about demographic characteristics, admitting diagnoses, acute and chronic health conditions, and medication usage.

\section{Main Predictor Variable}

The main predictor was the number of days of ICU delirium recorded as a time-varying covariate. Delirium was assessed Monday through Friday during the ICU stay using the Confusion Assessment Method ICU (CAM-ICU). The CAM-ICU was developed for use in critically ill, intubated patients, and details can be found at www.icudelirium.org. The CAM-ICU is a validated delirium detection tool with a sensitivity of 93 to $100 \%$ and a specificity of 98 to $100 \%$ and high interrater reliability $(\mathrm{kappa}=0.96)(11,15,16)$. Alertness was measured using the Richmond Agitation Sedation Scale $(17,18)$. If patients had evidence of stupor/coma, the CAM-ICU was not performed. If they had stupor/coma or were unavailable, the research nurse made three more attempts during the day to obtain the CAM-ICU. Chart review was used to detect delirium on Saturday and Sunday $(19,20)$. The whole medical record was reviewed daily for evidence of delirium using a validated chart review method $(19,20)$. The CAM-ICU algorithm was used to determine delirium status (16). When the CAM-ICU was 


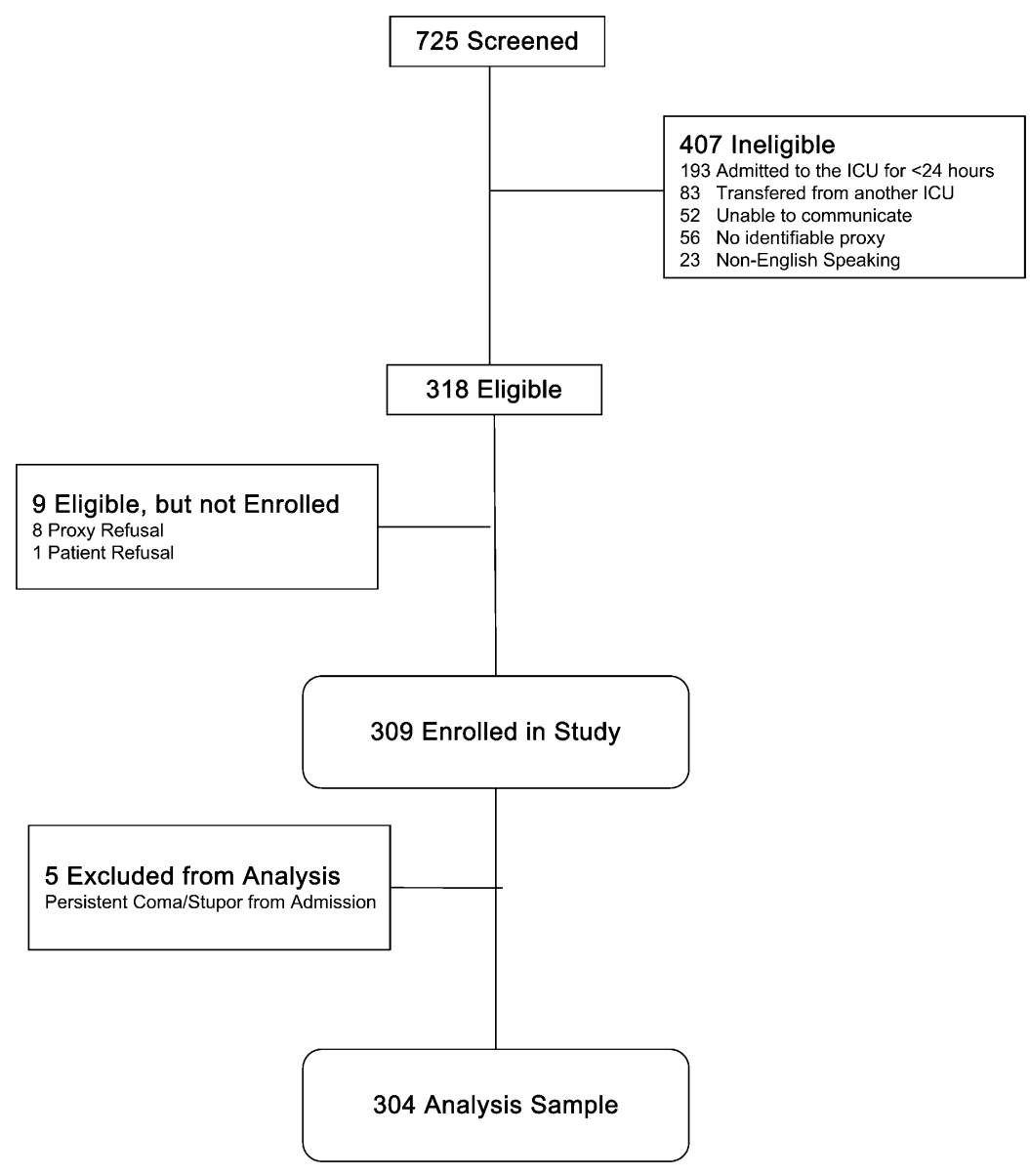

Figure 1. Patient enrollment screening and eligibility flow diagram.

unavailable, the chart review was used. If delirium occurred at any point during the 24-hour period, the day was considered a day "with delirium." Research nurses, who underwent training and interrater reliability testing for all key measures prior to study onset and at 6-month intervals, conducted study assessments. Interrater reliability was $100 \%$ between our two research nurses. The number of days of ICU delirium was calculated from the ICU admission date through ICU discharge. For participants who required readmission to the ICU within a few days of their initial discharge, days of delirium occurring during their ward stay were included in the total count of days of ICU delirium.

Of special interest is our interpretation of the relationship between delirium and coma/stupor. Papadopoulos discusses septic encephalopathy with delirium occurring within a pathological spectrum ranging from normal to coma/stupor (21). We follow the argument of Papadopoulos and note there is also evidence that the majority of patients progress from coma/stupor to delirium before returning to "normal" (2). For this reason, we have included the coma/stupor days in our count of days of delirium in the ICU (i.e., our main predictor variable).

\section{Outcome Variable}

The main outcome measure for this study was time to death during the ICU stay or within the first year after ICU admission. Time to death was calculated as the number of days from ICU admission that the person survived. Observations for the time-to-death variable were censored when study participants withdrew from the study or were alive at 1 year after ICU admission.

\section{Covariates}

Control variables were determined a priori based on prior literature and clinical experience. Preexisting dementia was evaluated using the Informant Questionnaire on Cognitive Decline in the Elderly $(13,22)$. Prior studies using this instrument have demonstrated its validity compared with cognitive testing of patients $(23,24)$, and we have previously documented its usefulness in ICU patients (13). Dementia was defined as an Informant Questionnaire on Cognitive Decline in the Elderly score $>3.3$; this cutpoint achieves a balance between sensitivity and specificity for detecting dementia $(13,24,25)$. Baseline function was assessed with the Katz Activities of Daily Living Scale and higherlevel function with Lawton's Instrumental Activities of Daily Living Scale (IADL) $(26,27)$. Other covariates included the Charlson Comorbidity Index score (28), medications on ICU admission and during the ICU stay, the Acute Physiology and Chronic Health Evaluation II score, (a measure of severity of illness [29]), and whether the patient was admitted to the ICU from the emergency room. Based on our prior work, we included the receipt of an opioid or benzodiazepine or any receipt of haloperidol during the ICU stay as control variables (30). We did not include receipt of propofol because only $7 \%$ of our patients received this medication.

\section{Statistical Analysis}

Descriptive statistics were ascertained as appropriate. An unadjusted analysis of the association between a five-level categorical version of the days of ICU delirium variable and the days of survival was conducted by creating Kaplan-Meier survival curves (31). For multivariable modeling, we used a Cox survival model (32) that included the number of days of ICU delirium main predictor and the length of ICU stay as cumulative time-varying covariates. Control variables for the multivariable model were selected on clinical grounds and were forced into the multivariable model. Covariates were represented as continuous or count variables only if they had a generally linear relationship to the mortality outcome. If clinical control variables were highly correlated (correlation coefficient $>0.40$ ), we used only the variable having the strongest association with the mortality outcome. Model fit was assessed using residual analysis and goodness-of-fit statistics. Bootstrapping was used to assess the reproducibility of the results for the main predictor of the multivariable model. 
TABLE 1. PARTICIPANT CHARACTERISTICS $(\mathrm{N}=304)$

Age in years, mean $\pm \mathrm{SD}$

Male gender, $\mathrm{n}(\%)$

Nonwhite race, $\mathrm{n}(\%)$

Dementia, $\mathrm{n}(\%)$

Direct admission to ICU from emergency room, $\mathrm{n}(\%)$

Admission to ICU from floor, $\mathrm{n}$ (\%)

Admitted to the ICU within $24 \mathrm{~h}$ of hospital admission, $\mathrm{n}(\%)$

Days between hospital and ICU admission, median (range)

Admission to ICU from other (rehab), n (\%)

Any impairment in activities of daily living, $n$ (\%)

Impairment in activities of daily living, median (IQR)

Any impairment in instrumental activities of daily living, $n$ (\%)

Impairment in instrumental activities of daily

living, median (IQR)

Charlson comorbidity index, mean \pm SD

ICU admitting diagnosis: respiratory disorder, $\mathrm{n}(\%)$

APACHE II score minus Glasgow coma component,

mean $\pm \mathrm{SD}$

Intubation, n (\%)

Receipt of opiods or benzodiazepines in the ICU, n (\%)

Receipt of propofol in the ICU, n (\%)

Receipt of haloperidol in the ICU, $\mathrm{n}(\%)$

ICU length of stay, median (IQR)

Total length hospital stay, median (IQR)

ICU delirium days, median (IQR)

ICU and floor/ward delirium days, median (IQR)

Post-ICU discharge, floor/ward delirium days, median (IQR)

Death in the ICU, n (\%)

Death within $1 \mathrm{yr}$ of ICU admission, n (\%)

Definition of abbreviations: APACHE = Acute Physiology and Chronic Health Evaluation; ICU = Intensive Care Unit; IQR = interquartile range.

* There are missing data for four subjects (dementia, $n=3$; Charlson, $n=1$ ).

Missing values on predictor and control variables were minimal (Table 1), so a complete case analysis was conducted. A $P$ value of 0.05 was considered to be significant for all two-sided statistical tests. SAS statistical software, version 9.2 (SAS Institute Inc, Cary, NC), was used.

\section{RESULTS}

The baseline characteristics of patients in the study sample are reported in Table 1. During the course of the 1-year follow-up, $153(50 \%)$ patients died. Of the total 153 who died, $48(16 \%$ of the total cohort) died during their ICU stay. Fourteen patients were withdrawn from the study, 13 due to transfer to another ICU and 1 due to the family's request. One participant did not complete the 1-year follow-up. All of these patients were censored. The median length of ICU stay was 5 days (range, 1-57 d), and the median duration of ICU delirium was 3 days (range, 0-46 d).

Kaplan-Meier survival curves were calculated using the fivelevel days of ICU delirium variable. Results for the log-rank statistic were highly significant, though the curves for the fourth and fifth levels were very similar (Figure 2).

Table 2 reports the multivariable Cox survival model results. The association between the number of days of ICU delirium and mortality was statistically significant (hazard ratio [HR], $1.10 ; 95 \%$ confidence interval [CI], 1.02-1.18) after adjusting for covariates. Multivariable model results remain the same when the model is pruned of nonsignificant $(P>0.10)$ clinical covariates (HR, 1.10; 95\% CI, 1.03-1.18). As a measure of reproducibility, bootstrapping confirmed the magnitude of the parameter estimate for the model's main predictor.

Other factors significantly associated with mortality included age, impairment in IADL, Charlson Comorbidity Index, and severity of illness on ICU admission.

\section{DISCUSSION}

This study provides new evidence for the importance of the number of days of ICU delirium as a risk factor for mortality. Previous ICU studies have found an association with the presence of delirium and mortality (6) but not between number of days of delirium in ICU and mortality. The results of this

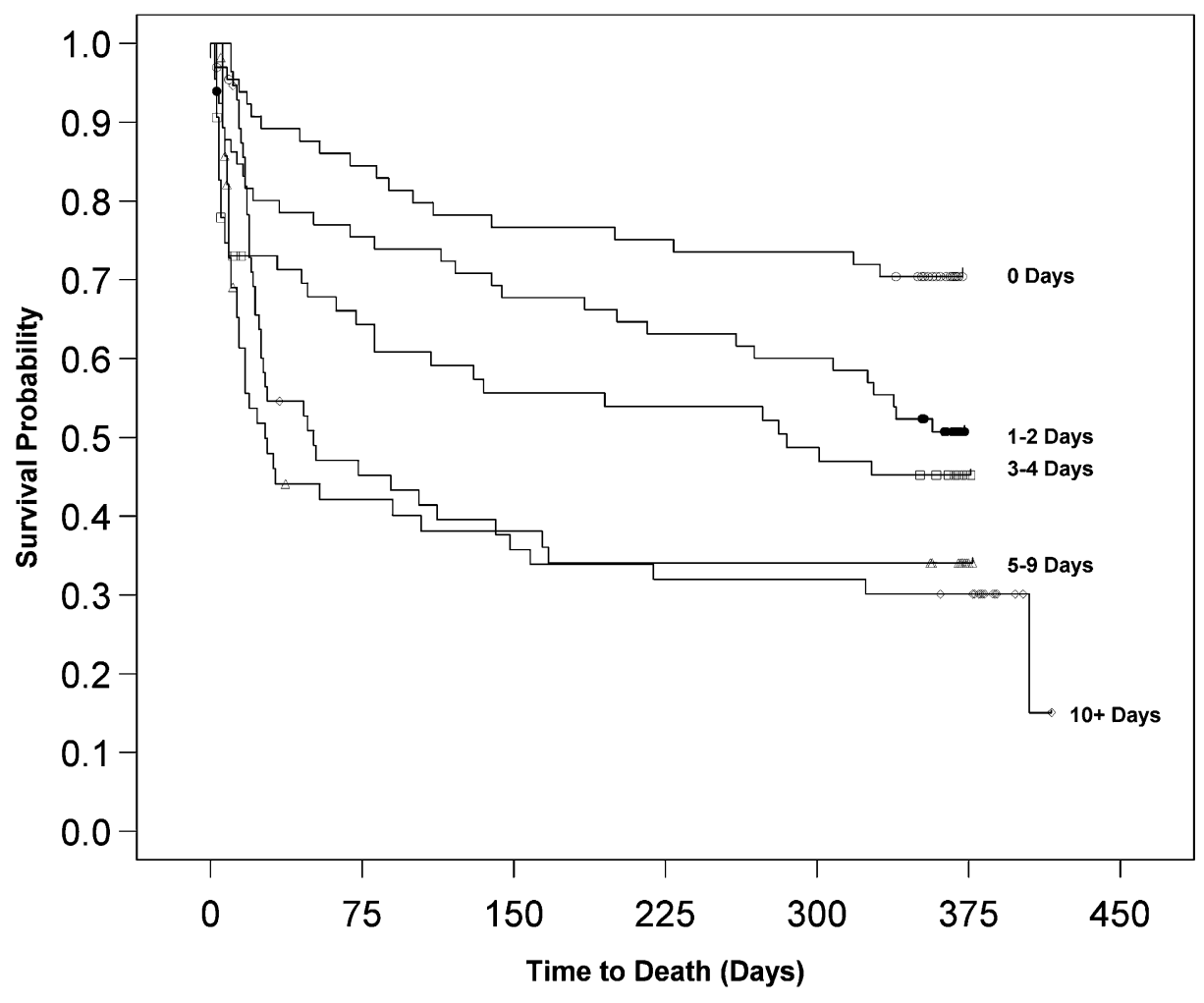

Figure 2. Kaplan-Meier survival curve for 1year mortality post-intensive care unit (ICU) admission (ICU delirium days predictor). Log-rank chi-square statistic $=28.3$; degrees of freedom $=3 ; P<001$. 
TABLE 2. COX SURVIVAL MODEL: PREDICTORS OF SURVIVAL 1 YEAR AFTER INTENSIVE CARE UNIT ADMISSION $(\mathrm{N}=300)$

\begin{tabular}{lcc}
\hline Variable & HR $(95 \% \mathrm{Cl})$ & $P$ Value \\
\hline ICU delirium days, time-varying, d & $1.10(1.02-1.18)$ & 0.01 \\
Age, yr & $1.03(1.01-1.05)$ & 0.009 \\
Male & $1.33(0.95-1.86)$ & 0.10 \\
Nonwhite race & $0.76(0.47-1.22)$ & 0.26 \\
Dementia & $1.07(0.72-1.58)$ & 0.74 \\
Instrumental activities of daily living (range, 0-6) & $1.30(1.16-1.45)$ & $<0.001$ \\
Admission from emergency room & $0.79(0.55-1.13)$ & 0.19 \\
Charlson comorbidity index & $1.21(1.11-1.31)$ & $<0.001$ \\
ICU admitting diagnosis: respiratory disorder & $0.71(0.48-1.05)$ & 0.09 \\
APACHE Il score minus Glasgow Coma Component & $1.05(1.02-1.08)$ & 0.001 \\
Intubation & $1.38(0.83-2.30)$ & 0.22 \\
Receipt of opioids or benzodiazepines in the ICU & $1.24(0.70-2.19)$ & 0.46 \\
Receipt of haloperidol in the ICU & $0.78(0.52-1.19)$ & 0.25 \\
ICU length of stay, time-varying, d & $0.98(0.93-1.05)$ & 0.59 \\
\hline
\end{tabular}

Definition of abbreviations: APACHE = Acute Physiology and Chronic Health Evaluation; $\mathrm{Cl}=$ confidence interval; $\mathrm{HR}=$ hazard ratio; $\mathrm{ICU}=$ intensive care unit.

study have important implications for the older hospitalized populations. Delirium should be considered as a significant, serious problem and treated as a possible contributor to mortality risk.

Delirium or brain dysfunction has often been thought of as a consequence of critical illness that would resolve when the acute illness resolved. Evidence is mounting that delirium itself is a strong predictor of increased length of mechanical ventilation, longer ICU stays, increased cost, prolonged neuropsychological dysfunction, and mortality $(5-8,11,33)$. Our results support those shown by Ely and colleagues that ICU delirium in mechanically ventilated patients is associated with 6-month mortality (6). Lin and colleagues demonstrated increased hospital mortality in 106 mechanically ventilated patients with delirium, but there was no difference in the mean duration of ICU delirium between survivors and nonsurvivors (11). In a small cohort of mechanically ventilated patients, days of delirium were associated with persistent cognitive impairment at 3 months (34). Our work supports the findings of Ely (6) and is novel in that it demonstrates that the duration of ICU delirium is associated with mortality up to 1 year after ICU admission even after adjusting for important potential confounders. The HR of 1.10 can be interpreted as saying that "each day of delirium in the ICU increases the hazard of mortality by $10 \%$." The cumulative effect of multiple days is multiplicative rather than additive.

Although delirium is a syndrome and there are likely multiple etiologic mechanisms that may lead to the clinical diagnosis, there is little knowledge concerning the pathogenesis of delirium in the ICU. We cannot point to a specific pathogenic process responsible for the association between delirium and increased mortality, but the pathogenic mechanisms need to be elucidated for the field to move forward.

Other factors significantly associated with 1-year mortality in our multivariable model, such as age, severity of illness, comorbidities, and impairment in IADLs, are consistent with other research on older hospitalized patients.

Although there are several studies that examine algorithms or medications for treating delirium in older hospitalized patients, these interventions have not been examined in an ICU setting (35-37). Although prevention of delirium is an ideal approach and an area of ongoing investigation, many older patients present to the ICU with delirium. In one study, $72 \%$ of the patients had delirium on their first ICU day (30). Although prevention of delirium within the ICU may be difficult, it may be possible to reduce delirium duration or severity. Schweickert and colleagues recently demonstrated a reduction in ICU delirium days with a protocol of early mobilization and occupational therapy (38).

Although treatment of the underlying critical illness is the first step in resolving delirium, there are ICU-related factors that can be addressed. One possibility that may be important in reducing delirium duration is a reexamination of the way we provide anxiety and pain control in the ICU setting. Several studies have documented the risk of delirium occurrence with the use of psychoactive medications in the $\operatorname{ICU}(3,12,30,39)$. Recently the receipt of benzodiazepines or opioids has been associated with increased delirium duration in a cohort of older ICU patients (30). A recent randomized controlled trial demonstrated that patients who received dexmedetomidine versus midazolam for sedation had less delirium (40).

The impact of reducing delirium duration on outcomes needs to be investigated further. Though current Critical Care and Psychiatric society guidelines recommend using antipsychotics to treat delirium, there are limited data to support these recommendations (41-44). Although antipsychotics, such as haloperidol, are often given to treat delirium, especially agitated delirium, there are no randomized controlled trials of delirium treatment in critical illness, and there are no FDAapproved medications for delirium treatment. If the number of days of ICU delirium is increasing mortality up to 1 year after ICU admission, prevention and treatment strategies need to be developed.

ICU admissions are an expensive component of healthcare, accounting for $1 \%$ of the US gross domestic product annually (45). In a study by Milbrandt, after controlling for potentially confounding variables, mechanically ventilated patients with one episode of delirium had a $40 \%$ increase in ICU and total hospital costs compared with patients with no delirium (8). In this study, the presence of delirium and severity, as measured by number of days of delirium, were independently associated with increased ICU and hospital costs. In addition to a possible mortality reduction, reducing cost is an important reason to investigate strategies aimed at reducing delirium duration.

A major strength of this study is the accurate delirium detection using validated methods that included CAM-ICU and chart review for delirium. A second strength is the very high participation rate and the small amount of missing data. There are several limitations in this study. First, this was a single-site study, and although the study cohort reflected a broad range of diagnoses, other types of critically ill patients should be investigated for mortality risk from chronic delirium, including patients in surgical ICUs. Second, there are limitations associated with the definition of duration of ICU delirium. The count of the number of days of ICU delirium might have been attenuated by deaths in the ICU or by discharge from the ICU. However, we investigated the possible impact of these limitations with sensitivity analyses and bootstrapping techniques, and these supplementary findings were consistent with our reported multivariable model results.

As we begin to confront a rapidly aging society, adequate high-quality disease management and care is needed. Given that a larger number of days of ICU delirium are associated with higher mortality, increased efforts to prevent, detect, and treat delirium are needed. Without appropriate preventive and management strategies for delirium, the burgeoning older population will face an increased burden of delirium and even higher mortality.

Conflict of Interest Statement: M.A.P. does not have a financial relationship with a commercial entity that has an interest in the subject of this manuscript. S.Y.J.K. 
does not have a financial relationship with a commercial entity that has an interest in the subject of this manuscript. S.V.K. received $\$ 50,001-\$ 100,000$ from the NIH in sponsored grants. T.E.M. does not have a financial relationship with a commercial entity that has an interest in the subject of this manuscript. K.L.B.A. does not have a financial relationship with a commercial entity that has an interest in the subject of this manuscript. P.H.V.N. holds $\$ 10,001-\$ 50,000$ in stock ownership or options from Vanguard Health Care Fund.

Acknowledgment: The authors thank Peter Charpentier for database development, Wanda Carr for data entry, Karen Wu and Andrea Benjamin for enrolling participants and interviewing family members, and the families, nurses, and physicians in the Yale Medical Intensive Care Unit.

\section{References}

1. Ely EW, Siegel MD, Inouye SK. Delirium in the intensive care unit: an under-recognized syndrome of organ dysfunction. Semin Respir Crit Care Med 2001;22:115-126.

2. McNicoll L, Pisani MA, Zhang Y, Ely EW, Siegel MD, Inouye SK. Delirium in the intensive care unit: Occurrence and clinical course in older patients. J Am Geriatr Soc 2003;51:591-598.

3. Pisani MA, Murphy TE, Van Ness PH, Araujo KL, Inouye SK. Characteristics associated with delirium in older patients in a medical intensive care unit. Arch Intern Med 2007;167:1629-1634.

4. Ely EW, Gautam S, Margolin R, Francis J, May L, Speroff T, Truman B, Dittus R, Bernard R, Inouye SK. The impact of delirium in the intensive care unit on hospital length of stay. Intensive Care Med 2001;27:1892-1900.

5. Ely EW, Jackson J, Gordon S, Shintani A, May L, Truman B, Dittus R, Gautam S, Bernard G, Speroff T, et al. Long-term neuropsychological deficits following delirium in mechanically ventilated ICU patients [abstract]. Am J Respir Crit Care Med 2002;165:A30.

6. Ely EW, Shintani A, Truman B, Speroff T, Gordon SM, Harrell FE Jr, Inouye SK, Bernard GR, Dittus RS. Delirium as a predictor of mortality in mechanically ventilated patients in the intensive care unit. JAMA 2004;291:1753-1762.

7. Jackson JC, Hart RP, Gordon SM, Shintani A, Truman B, May L, Ely EW. Six-month neuropsychological outcome of medical intensive care unit patients. Crit Care Med 2003;31:1226-1234.

8. Milbrandt EB, Deppen S, Harrison PL, Shintani AK, Speroff T, Stiles RA, Truman B, Bernard GR, Dittus RS, Ely EW. Costs associated with delirium in mechanically ventilated patients. Crit Care Med 2004; 32:955-962.

9. Thomason JW, Shintani A, Peterson JF, Pun BT, Jackson JC, Ely EW. Intensive care unit delirium is an independent predictor of longer hospital stay: a prospective analysis of 261 non-ventilated patients. Crit Care 2005;9:R375-R381.

10. McAvay GJ, Van Ness PH, Bogardus ST Jr, Zhang Y, Leslie DL, LeoSummers LS, Inouye SK. Older adults discharged from the hospital with delirium: 1-year outcomes. J Am Geriatr Soc 2006;54:1245-1250.

11. Lin SM, Liu CY, Wang CH, Lin HC, Huang CD, Huang PY, Fang YF, Shieh MH, Kuo HP. The impact of delirium on the survival of mechanically ventilated patients. Crit Care Med 2004;32:2254-2259.

12. Ouimet S, Kavanagh BP, Gottfried SB, Skrobik Y. Incidence, risk factors and consequences of icu delirium. Intensive Care Med 2007; 33:66-73.

13. Pisani MA, Inouye SK, McNicoll L, Redlich CA. Screening for preexisting cognitive impairment in older intensive care unit patients: use of proxy assessment. J Am Geriatr Soc 2003;51:689-693.

14. Pisani MA, Redlich C, McNicoll L, Ely EW, Inouye SK. Underrecognition of preexisting cognitive impairment by physicians in older icu patients. Chest 2003;124:2267-2274.

15. Ely EW, Inouye SK, Bernard GR, Gordon S, Francis J, May L, Truman B, Speroff T, Gautam S, Margolin R, et al. Delirium in mechanically ventilated patients: validity and reliability of the confusion assessment method for the intensive care unit (CAM-ICU). JAMA 2001;286: 2703-2710.

16. Ely EW, Margolin R, Francis J, May L, Truman B, Dittus R, Speroff T, Gautam S, Bernard GR, Inouye SK. Evaluation of delirium in critically ill patients: validation of the confusion assessment method for the intensive care unit (cam-icu). Crit Care Med 2001;29:13701379.

17. Sessler CN, Gosnell MS, Grap MJ, Brophy GM, O'Neal PV, Keane KA, Tesoro EP, Elswick RK. The richmond agitation-sedation scale: validity and reliability in adult intensive care unit patients. Am J Respir Crit Care Med 2002;166:1338-1344.

18. Ely EW, Truman B, Shintani A, Thomason JW, Wheeler AP, Gordon S, Francis J, Speroff T, Gautam S, Margolin R, et al. Monitoring sedation status over time in icu patients: Reliability and validity of the Richmond Agitation-Sedation Scale (RASS). JAMA 2003;289: 2983-2991.

19. Pisani MA, Araujo KL, Van Ness PH, Zhang Y, Ely EW, Inouye SK. A research algorithm to improve detection of delirium in the intensive care unit. Crit Care 2006;10:R121.

20. Inouye SK, Leo-Summers L, Zhang Y, Bogardus ST Jr, Leslie DL, Agostini JV. A chart-based method for identification of delirium: validation compared with interviewer ratings using the confusion assessment method. J Am Geriatr Soc 2005;53:312-318.

21. Papadopoulos MC, Davies DC, Moss RF, Tighe D, Bennett ED. Pathophysiology of septic encephalopathy: a review. Crit Care Med 2000;28:3019-3024.

22. Jorm AF. A short form of the informant questionnaire on cognitive decline in the elderly (IQCODE): development and cross-validation. Psychol Med 1994;24:145-153.

23. Jorm AF, Scott R, Cullen JS, MacKinnon AJ. Performance of the informant questionnaire on cognitive decline in the elderly (IQCODE) as a screening test for dementia. Psychol Med 1991;21:785-790.

24. McLoughlin DM, Cooney C, Holmes C, Levy R. Carer informants for dementia sufferers: carer awareness of cognitive impairment in an elderly community-resident sample. Age Ageing 1996;25:367-371.

25. Jorm AF. The informant questionnaire on cognitive decline in the elderly (IQCODE): a review. Int Psychogeriatr 2004;16:275-293.

26. Katz S, Ford AB, Moskowitz RW, Jackson BA, Jaffe MW. Studies of illness in the aged. The index of adl: a standardized measure of biological and psychosocial function. JAMA 1963;185:914-919.

27. Lawton MP, Brody EM. Assessment of older people: self-maintaining and instrumental activities of daily living. Gerontologist 1969;9:179186.

28. Charlson ME, Pompei P, Ales KL, MacKenzie CR. A new method of classifying prognostic comorbidity in longitudinal studies: development and validation. J Chronic Dis 1987;40:373-383.

29. Knaus WA, Draper EA, Wagner DP, Zimmerman JE. Apache II: a severity of disease classification system. Crit Care Med 1985;13: 818-829.

30. Pisani MA, Murphy TE, Araujo KL, Slattum P, Van Ness PH, Inouye SK. Benzodiazepine and opioid use and the duration of intensive care unit delirium in an older population. Crit Care Med 2009;37:177-183.

31. Kaplan EL, Meier P. Nonparametric estimation from incomplete observations. J Am Stat Assoc 1958;53:457-481.

32. Cox DR. Regression models and life tables (with discussion). $J$ R Stat Soc, B 1972;34:187-220.

33. Ely EW, Baker AM, Dunagan DP, Burke HL, Smith AC, Kelly PT, Johnson MM, Browder RW, Bowton DL, Haponik EF. Effect on the duration of mechanical ventilation of identifying patients capable of breathing spontaneously. $N$ Engl J Med 1996;335:1864-1869.

34. Jackson JC, Gordon SM, Girard TD, Thomasson JWW, Pun BT, Dun AJ, Canonico AE, Light RW, Shintani AK, Thompson JL, et al. Delirium as a risk factor for long term cognitive impairment in mechanically ventilated ICU survivors. American Thoracic Society International Conference. San Francisco; 2007. p. A22.

35. Inouye SK, Bogardus ST, Charpentier PA, Leo-Summers L, Acampora D, Holford TR, Cooney LM. A multicomponent intervention to prevent delirium in hospitalized older patients. N Engl J Med 1999; 340:669-676.

36. Kalisvaart KJ, de Jonghe JF, Bogaards MJ, Vreeswijk R, Egberts TC, Burger BJ, Eikelenboom P, van Gool WA. Haloperidol prophylaxis for elderly hip-surgery patients at risk for delirium: a randomized placebo-controlled study. J Am Geriatr Soc 2005;53:1658-1666.

37. Marcantonio ER, Flacker JM, Wright RJ, Resnick NM. Reducing delirium after hip fracture: a randomized trial. J Am Geriatr Soc 2001:49:516-522.

38. Schweickert WD, Pohlman MC, Pohlman AS, Nigos C, Pawlik AJ, Esbrook CL, Spears L, Miller M, Franczyk M, Deprizio D, et al. Early physical and occupational therapy in mechanically ventilated, critically ill patients: a randomised controlled trial. Lancet 2009;373:1874-1882.

39. Dubois MJ, Bergeron N, Dumont M, Dial S, Skrobik Y. Delirium in an intensive care unit: a study of risk factors. Intensive Care Med 2001;27: 1297-1304.

40. Riker RR, Shehabi Y, Bokesch PM, Ceraso D, Wisemandle W, Koura F, Whitten P, Margolis BD, Byrne DW, Ely EW, et al. Dexmedetomidine vs midazolam for sedation of critically ill patients: a randomized trial. JAMA 2009;301:489-499.

41. Trzepacz P, Breitbart W, Franklin J, Levenson J, Martini DR, Wang P; Work Group on Delirium. Practice guideline for the treatment of 
patients with delirium. American Psychiatric Association. Am J Psychiatry 1999;156:1-20.

42. Breitbart W, Marotta R, Platt MM, Weisman H, Derevenco M, Grau C, Corbera K, Raymond S, Lund S, Jacobson P. A double-blind trial of haloperidol, chlorpromazine, and lorazepam in the treatment of delirium in hospitalized aids patients. Am J Psychiatry 1996;153:231-237.

43. Jacobi J, Fraser GL, Coursin DB, Riker RR, Fontaine D, Wittbrodt ET, Chalfin DB, Masica MF, Bjerke HS, Coplin WM, et al. Clinical practice guidelines for the sustained use of sedatives and analgesics in the critically ill adult. Crit Care Med 2002;30:119-141.

44. Skrobik YK, Bergeron N, Dumont M, Gottfried SB. Olanzapine vs haloperidol: treating delirium in a critical care setting. Intensive Care Med 2004;30:444-449.

45. Socioeconomic status and health chartbook (U.S. Department of HHS publication phs 98-1232). Hyattsville, MD: US Dept of Health and Human Services; 1998. 